\title{
Politique
}

Politique

\section{Yves BÉLANGER et Laurent LEPAGE (Eds), L'administration publique québécoise : évolutions sectorielles 1960-1985, Sillery, Presses de l'Université du Québec, 1989, 226 p.}

\section{Luc Bernier}

Numéro 17, hiver 1990

Les nouveaux enjeux du politique

URI : https://id.erudit.org/iderudit/040659ar

DOI : https://doi.org/10.7202/040659ar

Aller au sommaire du numéro

\section{Éditeur(s)}

Société québécoise de science politique

ISSN

0711-608X (imprimé)

1918-6584 (numérique)

Découvrir la revue

Citer ce compte rendu

Bernier, L. (1990). Compte rendu de [Yves BÉLANGER et Laurent LEPAGE (Eds), L'administration publique québécoise : évolutions sectorielles 1960-1985, Sillery, Presses de l’Université du Québec, 1989, 226 p.] Politique, (17), 180-182.

https://doi.org/10.7202/040659ar d'utilisation que vous pouvez consulter en ligne.

https://apropos.erudit.org/fr/usagers/politique-dutilisation/ 
Yves BÉLANGER et Laurent LEPAGE (Eds), L'administration publique québécoise: évolutions sectorielles 1960-1985, Sillery, Presses de l'Université du Québec, 1989, 226 p.

Ce recueil de textes propose une série de «synthèses monographiques sur quelques-uns des principaux secteurs d'intervention de l'appareil étatique québécois depuis le début des années 60» (p. 10). Les différents auteurs retracent les principales lois qui ont encadré la modernisation de l'appareil administratif québécois depuis la mort de Duplessis ainsi que les différents rapports ou énoncés de politiques (réalisées ou non).

Dans le premier chapitre, Jacques Bourgault trace un portrait fort intéressant de l'évolution de «la carrière» des grands commis de l'État québécois depuis les réformes entreprises à la fin des années 50. Il explique comment leurs rapports avec la classe politique sont demeurés dans le vague statutaire ainsi que les particularismes socio-économiques de ce groupe unique d'employés de l'État.

Au chapitre deux, Julien Bauer traite de la syndicalisation dans le secteur public québécois qu'il caractérise comme une longue marche vers la centralisation. Selon lui, la syndicalisation de la fonction publique et la reconnaissance du droit de grève furent parmi les éléments les plus importants de la Révolution tranquille et occasionnèrent par la suite des soubresauts aussi fréquents que difficiles.

Dans le troisième chapitre, André Bernard retrace 25 ans de changements dans le domaine de la gestion financière du gouvernement du Québec. Ces modifications vont également dans le sens d'une plus grande centralisation et d'un contrôle plus serré.

Les chapitres suivants délaissent ces considérations qui touchent l'ensemble de l'appareil d'État québécois pour traiter de pans importants de l'activité gouvernementale. Laurent Lepage souligne la centralisation qui a marqué la modernisation de l'édifice scolaire québécois. Même son de cloche de la part de Pierre Tremblay qui discute l'intervention étatique dans le domaine social. Dans ces deux secteurs l'État est intervenu plus directement que dans le pas- 
sé et a diminué les pouvoirs des institutions régionales, surtout religieuses, déjà existantes.

Le sixième texte, celui de Yves Bélanger, porte sur l'administration de la main-d'oeuvre. Dans un premier temps, l'auteur souligne les principales caractéristiques des politiques québécoises dans ce secteur pour, dans un deuxième temps, revenir à sa mise en oeuvre.

Dans l'avant-dernier texte, Carolle Simard discute la difficile émergence du ministère des Affaires culturelles, de GeorgesÉmile Lapalme à nos jours, en passant par les divers énoncés de politiques publiés en 1965 et en 1976 à la veille de la défaite électorale de Robert Bourassa et en 1978 pour encadrer la loi 101.

Finalement, dans un texte intitulé «Décentralisation municipale et pouvoir technocratique», Pierre Delorme traite, lui aussi, de la modernisation de l'État québécois. Il retrace certains efforts d'aménagement et de partage des pouvoirs imposés par les technocrates québécois comme, par exemple, la logique de fonctionnement employée par les MRC.

Ce livre me semble des plus utiles et constitue un ouvrage de référence important. Il comble un vide évident dans la littérature existante. Les synthèses offertes sont bien faites et permettent de cerner l'évolution parfois chaotique de l'État québécois et de redécouvrir les références bibliographiques principales sur les sujets traités.

Je ne puis m'empêcher cependant d'espérer une refonte prochaine du volume. Pourquoi les textes d'un livre publié en 1989 se limitent-ils à cerner l'évolution de l'État québécois jusqu'en 1985 ? N'y aurait-il pas lieu de refaire une seconde édition du même livre en considérant les transformations suggérées dans les rapports Gobeil, Scowen et Fortier et l'élan des différents livres bleus, blancs ou verts qui ont suivi?

Je ne sais pas non plus quelle logique a présidé à l'inclusion ou l'exclusion de certains domaines de politiques. L'absence d'un chapitre d'introduction proprement dit laisse le lecteur dans le doute, guère bénéfique dans ce cas.

Dans une refonte, il pourrait être approprié d'ajouter quelques chapitres sur différents sujets oubliés dans cette première ver- 
sion. Pour prendre un exemple au hasard, la difficile constitution des appareils d'État dans le domaine des relations internationales mérite d'être étudiée. On pourrait aussi tenter d'expliquer pourquoi le ministère de l'Environnement demeure embryonnaire. De même, on peut se demander si le ministère de l'Industrie et du Commerce ne mériterait pas un chapitre à l'heure de la «garde montante» et du virage technologique encore à prendre.

Un sujet, traité ailleurs il est vrai, pourrait aussi faire l'objet d'une synthèse: la ou les politiques linguistiques. Aussi, malgré que le retour à la terre soit passé de mode, les politiques agricoles, le zonage pour prendre un autre exemple au hasard, occupent encore les campagnes et les fortunes électorales ou autres.

L'explosion démographique des lois, règlements et politiques du gouvernement au cours de ces années rend difficile une recherche plus approfondie. Néanmoins, ce qui manque le plus dans cet ouvrage c'est un essai cherchant à regrouper les diverses tendances théoriques employées et cherchant à présenter de façon cohérente ou à retracer la cohérence, s'il y en eut, des efforts gouvernementaux depuis 1960. Les politiques étudiées pourraient, surtout vu leur nombre limité, faire l'objet d'une formalisation théorique liant l'analyse au départ ou d'une généralisation plus poussée en conclusion de l'ouvrage. 